oClinital aldecture ox

\section{A CASE OF RENAL DISEASE ENDING IN APOPLEXY.}

\author{
BY W. H. BROADBENT, M.D., F.R.C.P., \\ PHYSICIAN TO ST. MARY'S HOSPITAT.
}

Gentumen,-The anatomical pieces before you tell a tale to the educated eye far more eloquent and impressive than any I can shape into words. There are the kidneys; there is the heart; there is the brain. The kidneys diminished in size--one especially so,-rough and granular on the surface, with here and there a small cyst, and damaged in their intimate structure. The heart enormously enlarged, weighing $19 \mathrm{oz}$. instead of $9 \mathrm{oz}$. or $10 \mathrm{oz}$. ,-the walls of the left ventricle greatly thickened; and this change not accounted for by any alterations of the valves, which are quite healthy and competent. The brain with a large ragged cavity in the right hemisphere, from which a great blood-clot has been extracted. To complete the chain of causation, we ought to have under the microscope, between the kidneys and the heart, and again between the heart and the brain, some of the minute arterioles from various parts, showing the muscular hypertrophy of their coats, demonstrated and explained so admirably by Dr. George Johnson. The successive links of the deadly chain would then run thus:-Disease of the kidneys gave rise to accumulation within the blood of excretory materials which these organs should have eliminated; the circulation of the blood, thus rendered impure, was resisted by the stopcock action of the muscular coat of the minute arteries for the defence of the tissues; the heart, feeling this resistance, and not recognising its conservative character, began to act with increased vigour to overcome it and carry on the circulation; while the arteries, on the other hand, contracted all the more energetically: and so, in obedience to the law that increased exercise of function by muscular fibre induces hypertrophy of structure, heart and arteries, in their strife one against the other, became hypertrophied. But when the heart is acting with increased power on the one hand, and the minute arteries are continuing their resistance on the other, the blood is at high pressure within the vessels; and if there is a weak spot anywhere the vessel will be in danger of bursting. This is what has happened in the present case, the weak point having been found in the small vessels penetrating the brain-substance from the middle cerebral artery in the posterior part of the Sylvian fissure.

The poor woman from whose body these morbid specimens were taken was admitted under my care in September. She was for a time in the Alexandra ward, more recently in No. 2 bed in the Victoria ward, where some of you have repeatedly seen her with me, little anticipating from her appearance the sudden fate which has overtaken her. Her illness, according to her own account, dates from an attack of hemiplegia of the left side two years since, while preg. nant. This seems to have been severe, as it was six months before she was able to walk about again. She got over her confinement, however, without any difficulty or complication. After regaining a fair state of health, she had within the last few months been complaining of weakness, loss of appetite, imperfect digestion of her food, discomfort after eating, \&c.

She did not look particularly ill, and she presented no appearance suggestive of any special disease. Very slight traces of her old paralysis remained. Investigating the causes of her complaints, we came at once upon the fact that the urine contained albumen. This we might have suspected from the occurrence of hemiplegia during preg. nancy. The amount of albumen varied considerably; there was never much, and sometimes it was absent altogether. The urine was pale, not perfectly clear, acid in reaction, and of a specific gravity of 1018, as a rule-never, so far as I know, below 1015-sometimes as high as 1020. Now this No. 2526. is a high specific gravity for the state of kidney we supposed to exist-contracted granular kidney,-and at times cast a momentary doubt on the diagnosis. I account for it now by the fact that in one kidney the morbid change was still in an early stage. We obtained little microscopic evidence as to the kidney mischief-a few particles of damaged renal epithelium, and rare and questionable fragments of small granular casts. There was no trace of dropsy or œdema, and never had been; but in this particular affection of the kidneys we do not expect it, and, as I have said, there was no marked renal look.

But we had evidence from another source in favour of our diagnosis-the indirect evidence of the vascular system. I frequently pointed out to you the peculiar character of the pulse. On asking a student to describe it, the invariable report was that it was weak; and to the fingers placed lightly on the vessel that was the impression conveyed; there was, in effect, very little pulsatile movement in the artery. But then it was very large and very hard, and the vessel slipped and rolled about under the finger like a bit of thick whipcord, reminding one of the vas deferens among the structures of the spermatic cord, only much larger; and when it was attempted to control the pulsation by pressure with the finger nearest the heart, it was found to be a very difficult matter. Press as one would almost, the pulsation could still be felt by the two fingers on the distal part of the vessel. The first impression of weakness was thus at once removed, and the pulse recognised to be extremely strong; it was the long, hard, large pulse of high arterial tension, which gives a sphygmographic trace of gradual ascent, low elevation, rounded summit, and gentle, unbroken fall.

Then as to the heart: the area of dulness over it was extensive; its impulse was a powerful and widespread heave; the apex-beat was conspicuously evident to both eye and hand below and to the left of its normal situation. This was of course evidence of considerable hypertrophy. A mitral murmur was reported to me by my resident medical officer when the patient was first admitted, but I did not succeed in hearing it: I thought I distinguished once or twice a smooth, feeble, systolic, tricuspid murmur; and a hæmic pulmonary murmur could sometimes be heard. I attached no importance to any murmur found to be present; but modifications of the heart-sounds of extreme interest were detected-namely, reduplication of the first sound over the inter-ventricular septum, extinction of the first sound and exaggeration of the second over the aorta. These have recently been beautifully explained as phenomena of high blood-pressure by Dr. Sibson. To distinguish the reduplication you must either have the double stethoscope and place one mouth over the right ventricle and the other over the left, or the common stethoscope must be planted over the septum between the ventricles. At the apex or over the sternum the first sound is pure and single; it is only when the sound given out by both the ventricles in their contraction is conveyed to the ear that a doubled sound is heard. This alone would suggest what is clearly brought out by manœuvring with the double stethoscope-namely, that the reduplication is due to the want of exact synchronism in the contraction of the two ventricles: that of the left is retarded by the extreme resistance to the entry of more blood into the already distended arteries, and thus the right gets a slight start. Each ventricle produces sound by its systole; and when, from any cause, the normal coincidence of the two is disturbed, the first sound of the heart, which is compounded out of the two sounds of the ventricles, is reduplicated. The diminution or extinction of the first sound over the aorta, again, is explained by the arterial tension, which prevents the left ventricle from throwing its contents rapidly into the aorta, and renders its action more gradual; while the increased pressure within the aorta, forcing back the semilunar valves with undue violence, causes the second sound to be louder.*

The bigh arterial tension so obviously indicated by the signs I have mentioned, which I repeatedly pointed out in my visits to the ward, and the cardiac hypertrophy, were corroborative of the diagnosis of contracted granular kidney. Another corroborative sign I looked for in vain: I mean

* The tension of the arterial walls is an element in the production of the second sound, but this and otber points were not discussed. Nor is what has been said intended as a complete exposition of the relation of the modification of the sounds to the arterial tension; it was rather a reminder to students already familiar with Dr. Sibson's teaching. 
the characteristic changes in the retina. My note of the appearances presented by the fundus of the eye on ophthalmoscopic examination is as follows:- The fundus of the eye generally seemed paler than usual, the optic disc a little more pink; so that, though the disc was well defined, the difference between it and the surrounding retina was less marked than usual. It was small, had no appearance of elevation, and presented in the centre a white spot from which the ressels issued. The retinal artery seemed smaller than usual. No white spots or hæmorrhages were seen.

The objects to be kept in view in the treatment of a case of this kind are simple and obvious. We cannot hope to undo the structural mischief already done in the kidney; in some cases we may perhaps arrest the morbid process when it is traceable to some known cause, as alcoholic excess, \&c.; but, generally speaking, what we have to do is to avert as long as possible the consequences-the accumulation of urea or other poisonous substances in the blood, and the loss of strength and deterioration of structure to which the state of the blood gives rise. The bowels must be kept open, the action of the skin must be encouraged, so as to secure whatever vicarious elimination their excretions may afford; the diet must be regulated and digestion aided; and it is generally beneficial to give the tinct. ferri muriatis. This was the line of treatment we followed, and our patient seemed decidedly better; she was relieved of the symptoms which caused her to seek admission; the reduplication of the first sound of the heart was no longer heard; the artery at the wrist was not so full and hard; once, indeed, for a few days during a brief pyrexia the peculiar character of the pulse was lost altogether; and it was expected she would soon leave the hospital greatly relieved.

The dangers to which the subjects of this form of Bright's disease are exposed are, on the one hand, uræmic poisoning, so called when the nervous system is affected, or secondary inflammation of important organs, or effusions into the great cavities, from disturbance of the normal relations between blood and tissue; or, on the other hand, rupture of a vessel in the head as a consequence of the great arterial tension. We had no special reason to anticipate any of these unfavourable effects immediately. The specific gravity of the urine seemed to guarantee the elimination of a fair proportion of the urinary constituents; the patient had not the well-known renal look; she was not old; there were no advanced retinal changes, and the arterial tension was reduced. There was, however, an element of danger, of which I was not for some time aware. The woman was five or six months pregnant. She had stated all the time she was under observation that the catamenia were regular, and nothing had occurred to lead to a physical examination of the abdomen till shortly before her death, when she mentioned some uneasy sensation in the hypogastrium. I proceeded to see if any cause for this was to be found, and, coming upon the uterus, I said at once, "Why, you are pregnant." This the patient strenuously denied, repeating her statement that she had been quite regular, and was, in fact, menstruating at the time; saying, also, that the tumour I felt had been there for some time. She was a married woman, and had no reason for concealing her pregnancy, unless, as it has occurred to me since, she had apprehensions of danger attending it, which made her wish to blind herself to its existence; and I accepted her denial pro tem., with the intention of making further investigation when the catamenial period was over. Now, without saying at all that the pregnancy was an important factor in the causation of the hæinorrhage, the coexistence of pregnancy and albuminuria is a serious matter, which, had it been fully known to me, would have led me to look on the immediate future of the patient with more apprehension. But this is a point into which I cannotenter fully now, and we must come to the fatal attack, which was preceded, and perhaps determined, by two or three days of more than usually obstinate eonstipation.

At about 3.30 on the morning of Thursday, November 30th, she was apparently as well as usual, and asked the nigbt-nurse for drink. A few minutes later her right leg and hand were knocking against a screen which stood by her bedside. When the nurse went to her, the right limbs were thrown about, but more as if the movements were voluntary than convulsive, while the left limbs were rigid, contorted, and twitching; the face was at first distorted. $B y$ the time the sister of the ward and the resident medical officer reached her the movements of the right side were less violent; the face was equal on the two sides, but the rigidity of the left limbs was the same; the right pupil was greatly dilated, the left much contracted. The patient recognised both, and gave their names, but she could give no account of herself, or of what she felt. Later she was more quiet, but from time to time tossed off the clothes with the right hand or leg, and rubbed her head with this hand, while the left limbs remained rigid and powerless, and were at intervals shaken by a peculiar tremor; the left hand was powerfully pronated, and the fingers and wrist flexed; she resisted when the eyes were opened, seemed to resent disturbance, evidently felt a pinch on the right side, but gave no indications of sensation on the left half of the body; she swallowed fluids pretty well; no signs of consciousness beyond those first mentioned could be elicited. Soon after 3 P.M. convulsive movements again came on, and she died almost instantly. The tongue was bitten.

These details are chiefly interesting in connexion with the seat and extent of the hæmorrhage. The clot lay to the outer side of the right corpus striatum and thalamus, and had torn through the fibres passing from them into the hemisphere. It extended along nearly the whole length of the ganglia, but did not turn round the anterior end of the corpus striatum. Its upper part was on a level with the intra-ventricular surface of these bodies. Inferiorly it was separated by a very thin stratum of nervous matter from the fissure of Sylvius, and, in my opinion, the source of the bleeding was the small branches of the middle cerebral artery here penetrating the brain-substance. Now, my interpretation of rigidity in the paralysed parts at the onset of apopletic hemiplegia is injury near, but not extensively or deeply involving, the motor ganglia or tract. Destructive lesion of the motor apparatus appears to leave the paralysed limbs relaxed; pressure upon, or "irritation" of it, while its cells and fibres are still in continuity, appears to me to render them rigid. This view of mine may, of course, at any time be overthrown by facts inconsistent with it; but, at any rate, it has the support of this case, and I could give you many others.

One question remains: "Could anything have been done to postpone the fatal issue when once the rupture of the vessel had occurred?" I do not know, but had I seen the patient at once I should have bled her, simply on the ground of the antecedently known high arterial tension. We can all see now that, at least, this would have done no harm. You will not, however, from this statement infer that I recommend or practise venesection in apparent apoplexy as a rule; the very contrary is the case, and on some future occasion I hope to show you reasons for this.

Looking once more at the morbid specimens, and taking a backward glance at the history of an attack of hemiplegia in a previous pregnancy, at the comparatively slight evidence of kidney disease offered by the urine and general appearance of the patient, and at the assistance to a correct diagnosis and warning as to the kind of danger to be apprehended afforded by attention to the signs of arterial tension in the pulse and in the modifications of the heart sounds, and remembering also, as I always shall, the existence of pregnancy at the time of the final apoplexy, you will find the case full of interest and instruction.

\section{CONTRIBUTIONS}

ON THE

\section{PHYSIOLOGY \& THERAPEUTICS OF FOOD.}

BY F. W. PAVY, M.D., F.R.S.,

LROTURER ON PHXSIOLOGX AND PHYSICIAN AT GUX'S HOBPITAL.

No. V.

THE PURPOSES SUBSERVED BY THE NITROGENOUS PRINCIPLES AS ALIMENTARY MATTER.

FIRsT in importance is the office fulfilled by affording a supply of material for the growth primarily, and for the renovation secondarily, of the tissues. Wherever vital operations are going on, there nitrogenous matter is present, forming, so to speak, the spring of vital action. Although non-nitrogenous matter contributes in certain ways towards the maintenance of life, yet it is nitrogenous matter 